\title{
Density versus Quality in Health Care Provision: Using Household Data to Make Budgetary Choices in Ethiopia
}

\author{
Paul Collier, Stefan Dercon, and John Mackinnon
}

\begin{abstract}
Usage of health facilities in Ethiopia is among the lowest in the world; raising usage rates is probably critical for improving health outcomes. The government has diagnosed the principal problem as the lack of primary health facilities and is devoting a large share of the health budget to building more facilities. But household data suggest that usage of health facilities is sensitive not just to the distance to the nearest facility but also to the quality of health care provided. If the quality of weak facilities were raised to that currently provided by the majority of facilities in Ethiopia, usage would rise significantly. National data suggest that given the current density and quality of service provision, additional expenditure on improving the quality of service delivery will be more cost-effective than increasing the density of service provision. The budget allocation rule presented in the article can help local policymakers make decisions about how to allocate funds between improving the quality of care and decreasing the distance to the nearest health care facility.
\end{abstract}

This article combines household survey data on health care choices in rural Ethiopia with budget data on the costs of health provision to analyze the tradeoff between the density of service provision and its quality. We develop a budget allocation rule that can be used in local decisionmaking. National data suggest that given the current density and quality of service provision, additional expenditure on improving the quality of service delivery will usually be more costeffective than increasing the density of service provision.

The focus is on the usage of health services rather than health outcomes. ${ }^{1}$ The link from usage to outcomes is complex. For example, Ethiopian health care

Paul Collier is Director of the Development Economics Research Group at the World Bank. His e-mail address is pcollier@worldbank.org. Stefan Dercon is a University Lecturer in Economics at Oxford University, linked to the Centre for the Study of African Economies. His e-mail address is stefan.dercon@economies.ox.ac.uk. John Mackinnon is an independent researcher and advisor on development issues. His e-mail address is jwm1962@aol.com.

1. Health outcome data, in particular adult nutrition and functioning data, are also available but were not included in the analysis. In principle, the links among distance, quality of health services, and outcomes can be fruitfully analyzed (examples are in Lavy and others 1996, and Thomas, Lavy, and Strauss 1996). However, strong seasonality in nutritional outcomes and the importance of controlling for health

DOI: $10.1093 /$ wber/lhf003

(C) 2002 The International Bank for Reconstruction and Development / THE WORLD BANK 
providers use the opportunity provided by curative visits to provide preventative treatment, so that the impact of health care on the illness that motivates the visit is likely to underestimate the overall contribution of usage to health.

In Ethiopia usage is much lower than in most other low-income countries. In 1996 only 9 percent of the population reported visiting a modern health facility during the past two months (Dercon 2000). This compares with 14 percent in Kenya, also based on a two-month recall period (Appleton 1998); 13 percent in Ghana, based on a four-week recall period; and 15 percent in Côte d'Ivoire, based on a four-week recall period (Lavy and Germain 1994, Dor and Van der Gaag 1988). These differences exist despite far worse health outcomes in Ethiopia. ${ }^{2}$ Among those who sought treatment, the vast majority relied on public facilities-not surprising in a country in which in 1999 more than 90 percent of rural health clinics (centers and stations) were owned by the government (Ministry of Health 1999). This reliance on public facilities distinguishes Ethiopia from other Sub-Saharan countries. In Côte d'Ivoire, for example, only about 40 percent of households relied on public facilities; in Kenya only about a third did so. Thus there is a reasonable presumption that poor health outcomes are partly caused by the atypically low usage of health facilities and that policy toward public provision will continue to be important in rectifying it. ${ }^{3}$

Policy to increase usage in Ethiopia currently focuses on increasing the physical coverage of facilities. This approach is based on the belief that distance is the main disincentive to using services. Increased coverage is very costly in terms of both the capital costs of building facilities and the fixed recurrent costs of running them. The policy thus squeezes variable recurrent expenditure per facility, reducing staffing and the supply of material inputs, such as drugs, and worsening the quality of service provision. In a highly revenue-constrained environment, there is a sharp tradeoff between reducing the distance to health facilities and improving their quality.

To the extent that existing facilities have spare capacity, increasing the quality of services may increase usage. A dollar spent on increasing the quality of service provision may increase usage by more than a dollar spent on increasing the number of facilities. In this case, aside from considerations of equity, improving quality dominates building new facilities because there is a larger increase in usage and both existing and new users get better services. Only if the reverse holds (so that services for new users are at the expense of services for existing users), is there a quantity-quality tradeoff.

endowments make this analysis beyond the scope of this article. For a detailed analysis of the dynamics of adult nutrition in Ethiopia and the link with illness and health care, see Dercon and Krishnan (2000).

2. The World Health Report (wHO 2000) estimates male under-age-five mortality rates at 100 per thousand for Kenya, 145 for Côte d'Ivoire, and 188 for Ethiopia, with adult mortality rates also higher in Ethiopia. In 1994 life expectancy in Ethiopia was estimated to be only about 43 years for men-well below the African average of 52 years.

3. Nevertheless, in the econometric model, the response to increased spending on public services and the impact on usage of private health providers will have to be taken into account (Filmer, Hammer, and Pritchett 1997). 
The responsiveness of health care demand to the distance from facilities is well established. By contrast, until recently, demand responsiveness to the quality of health care has been largely ignored. Recent work has pointed to the importance of including quality variables. (See, for example, Akin and others 1986, Hotchkiss 1993, Lavy and Germain 1994, Lavy and others 1996, Litvack and Bodart 1993, 1995, Mwabu, Ainsworth, and Nyamete 1993, Thomas, Lavy, and Strauss 1996. For an overview see Alderman and Lavy 1996.) Distance and quality are now recognized to be jointly important in determining usage.

This article applies similar techniques in Ethiopia. The distance-quality tradeoff has not previously been studied in such a deprived environment. The article further innovates by relating household behavior to budgetary expenses. To date the main policy focus of research on the demand effects of health care quality has been on user fees: if fees raise quality sufficiently, they can enhance usage. This article is concerned with the budgetary choice between government expenditures on capital programs versus recurrent health expenditures. That is, it takes total health care financing as given. Clearly, in the distance-quality tradeoff the main choice is one of budget allocation rather than cost recovery. By focusing on the distance-quality tradeoff we do not mean to imply that this is necessarily the most important issue in the allocation of public expenditure on health care. However, it has been neglected, because it is less obvious than tradeoffs such as clinics versus hospitals.

Section I formalizes the determination of demand by density and quality and discusses the relation between demand and welfare. Section II describes health provision in Ethiopia. Section III presents regression results on the demand for health care, comparing the effects of the quantity and quality of the provision of clinics on the quantity of health service usage. Section IV estimates budgetary costs of increased quantity of provision and improved quality of services and derives the relative cost-effectiveness of capital and recurrent expenditures. Section $\mathrm{V}$ summarizes the article's main findings.

\section{A Formal Framework for Analyzing the Effects of Quality and Distance on Usage of Health Care}

The government is assumed to want to maximize health outcomes subject to a budget constraint and the behavior of the representative household. The instruments the government has are the quality and the density of the primary health care network. This is a principal-agent problem in which the government needs to take into account the effects of its instruments on household demand for health care. Households are assumed to be characterized by a utility function in which health is an argument. This is the simplest way to represent the value placed by households on health in a static framework: ${ }^{4}$

4. The alternative-incorporating the likely effects of health on future income-would require an explicitly dynamic model. For an extensive survey on modeling the demand for health care, see Behrman and Deolalikar (1990) and Strauss and Thomas (1995). 


$$
U=U(H, C)
$$

where $H$ is a measure of health and $C$ is consumption excluding health. Time may be spent either in providing labor or in visiting health facilities:

$$
L=l+t(D) \cdot V
$$

where $L$ is the endowment of time, $l$ is labor, $D$ is the distance from facilities, $t$ is the time spent per visit to a clinic, and $V$ is the household's demand for visits to health facilities. We could simply assume that time is a linear function of distance; however, doing so ignores the possibility that people substitute into faster forms of transport as distance increases. In this article we use data on distance rather than time, and the form of the function is not important. The full income budget constraint is given by

$$
w \cdot L=C+F \cdot V+w \cdot t(D) \cdot V
$$

where $w$ is the real wage rate and $F$ is the user charge for health care.

The amount of health actually achieved is determined by a production function in which both demand and the quality of facilities play a part:

$$
H=H(C, V, Q)
$$

where $Q$ is quality.

For simplicity these functions are treated as deterministic; the stochastic nature of health outcomes is important in many contexts but does not affect this model.

The household chooses $L$ and $V$ to maximize equation (1) subject to equations (2-4). This problem yields demand functions both for health and for health care:

$$
\begin{aligned}
& H=h(D, Q, F, w) \\
& V=V(D, Q, F, w) .
\end{aligned}
$$

Our concern is with the demand functions, in particular the partial derivatives of the demand function for health care with respect to distance and quality. Empirical work has shed light on other derivatives of the demand function. Gertler and van der Gaag (1990) use the effects of distance on usage to estimate the effects of price on usage; Mwabu, Ainsworth, and Nyamete (1993) use the effects of seasonal movements in the cost of time to isolate the substitution effects of increases in the cost of time, finding that people visit clinics less in the busy season. Quality effects have been researched by Lavy and Germain (1994), Lavy and others (1996), and Thomas, Lavy, and Strauss (1996). Although changes in usage do not directly tell us about the change in welfare, they do have implications about the effectiveness of medical care. Because usage of health care has an opportunity cost in terms of consumption, we can distinguish between an income effect and a pure substitution effect in the choice between health outcomes and consumption. A reduction in distance 
is a price reduction in usage and, as a result, in health outcomes. As long as health is a normal good, both the income and substitution effects work to increase the consumption of health outcomes and hence of usage. By contrast, an improvement in quality does not reduce the cost of usage but rather its effectiveness. Hence fewer visits will be needed to maintain a given health outcome. Improved quality thus directly lowers the price of health outcomes. Although there will be both an income and a substitution effect increasing the consumption of health outcomes, this need not imply increased usage of health services. Increased usage of health services would require reduced consumption of other goods and so will come about only if the substitution effect into improved health is sufficiently strong to outweigh the income effect, which tends to increase consumption of other goods and so reduce visits.

This can be seen in a simplified example of the model. Let the health production function (equation [4]) take the form

$$
H=V \cdot Q
$$

so that we abstract from any effect of consumption onto health. Let the opportunity cost of visits in terms of consumption take the form

$$
C=w \cdot L-D \cdot V
$$

so that we abstract from user charges and make the cost of distance linear in distance. Finally, let the utility function take the form

$$
U=H . C \text {. }
$$

The optimal number of health care visits is now:

$$
V^{*}=w \cdot L / 2 D \text {. }
$$

The demand for visits is thus invariant with respect to quality while being a decreasing function of distance. In this case the income and substitution effects of a change in quality precisely net out. This is not a general result but depends on the functional form of the health production function and the utility function. For example, if the health production function takes the form

$$
H=V^{Q}
$$

then the optimal number of health care visits becomes

$$
V^{*}=\frac{Q \cdot w \cdot L}{(1+Q) D}
$$

so that the derivative with respect to quality becomes strictly positive, whereas the derivative with respect to distance remains strictly decreasing. (Note that the quality index developed later is bounded by 0 and 1 , so that equation [11] is concave in visits.)

Given the objective of maximizing health outcomes, the government's allocation of spending between recurrent and capital spending must be such as to gen- 
erate a level of quality and a density of provision that maximize health outcomes for given overall expenditures. ${ }^{5}$ Formally,

$$
G=r \cdot Q-c \cdot D
$$

where $G$ is the government health budget, $r$ is the unit price of an improvement in quality, and $c$ is the unit price of a reduction in the distance to the health facility.

The government maximizes $H$ subject to its budget constraint (equation [13]) and the demand functions for health and health care (equations [5] and [6]). It must equalize the marginal effects of its expenditures on quality and density on the health outcome of the representative household. That is,

$$
\frac{\frac{d H}{d Q}}{\frac{d H}{d D}}=-\frac{r}{c}
$$

In general, expenditure on quality affects health outcomes through two routes, a direct increase in the efficacy of a given level of usage and an indirect change in the amount of usage, which as we have seen can be positive or negative. That is,

$$
\begin{gathered}
\frac{\frac{d H}{d Q}}{\frac{d H}{d D}}=\frac{\frac{\delta H}{\delta V} \cdot \frac{d V}{d Q}+\frac{\delta H}{\delta Q}}{\frac{\delta H}{\delta V} \cdot \frac{d V}{d D}} \\
=\frac{\frac{d V}{d Q}}{\frac{d V}{d D}}+\frac{\frac{\delta H}{\delta Q}}{\frac{\delta H}{\delta V} \cdot \frac{d V}{d D}}
\end{gathered}
$$

Because the second term of expression (16) is negative, the optimum must be characterized by

$$
-\frac{r \frac{d V}{d Q}}{c \cdot \frac{d V}{d D}}<1
$$

In the empirical application in section III we are not observing health outcomes but the differential impact of quality and density on usage. We can nevertheless test the efficiency of allocation of health care expenditures by testing whether they meet the condition set out in expression (17). That is, because improving quality raises health outcomes both through an efficacy effect and a usage effect whereas reducing distance works only through a usage effect, effi-

5. The implications of the government maximizing utility rather than health outcomes are more complicated to analyze. 
cient allocation will require that the marginal impact on usage of a unit of expenditure on improved quality should be less than the marginal impact of a unit of expenditure on increased density.

Finally, we introduce a complication that reflects the dual nature of health care provision in Ethiopia between the public and private sectors. Both sectors maintain rural facilities, even if 90 percent of the modern facilities are public. The government can directly improve quality and reduce distance only with respect to its own facilities. The government decision problem remains as characterized, conditional on the demand for health and health care by private agents, though with $V$ redefined as total usage. However, there is an additional substitution effect from the usage of private facilities. How such a substitution is valued by the government depends on the efficacy of private provision. If private facilities are of lower quality than public facilities, condition (17) is unaffected. If private facilities are of better quality than public facilities, an increase in overall usage would be the net effect of a reduction in the usage of good facilities more than offset by an increase in the usage of poor facilities. Such a change in usage could even reduce overall health states, so that $\mathrm{d} H / \mathrm{d} V$ could potentially be negative. This would reverse the inequality in condition (17) as a condition for allocative efficiency but reinforce its core result. Because the effect of increased overall usage, $V$, on health outcomes would now be negative, the government would need to reduce its expenditure on distance reduction. Indeed, expenditure on distance reduction should be reduced until $\mathrm{d} H / \mathrm{d} V$ becomes positive, at which point condition (17) would again apply. Expenditure on distance reduction greater than that implied by condition (17) is always excessive.

\section{Health Care Provision in Ethiopia}

Between 1987 and 1996 annual per capita government spending on health facilities averaged just \$1.40 in constant 1987 U.S. dollars-far below the African average and indeed among the lowest in the world (World Bank 1996). Given these low levels of expenditure it is not surprising that provision is inadequate in terms of both density and quality. Facilities are thinly and unevenly spread, so that many households are far from clinics. Recent national sample data suggest that about 40 percent of rural households live more than $10 \mathrm{~km}$ from the nearest health facility (Central Statistical Authority 1999).

The services provided are often deficient. Clinics lack drugs and basic equipment. A government survey of facilities found that most lacked more than a quarter of the drugs rated as essential and a quarter lacked a refrigerator in which to store them. ${ }^{6}$ These indicators appear worse than in other African countries.

6. The data-the most recent official statistics available—are from the sector investment office of the Ethiopian government and are based on a sample survey of 57 government health stations and centers in rural areas in 1995. 
In Nigeria only about 28 percent of public health facilities lack drugs (Akin and others 1995); in Ghana about a third of public health facilities lack drugs (Lavy and Germain 1994). In Kenya public facilities lack antibiotics on average for about a tenth of the year (Mwabu, Ainsworth, and Nyamete 1993). ${ }^{7}$

The budgetary choice between the quantity of facilities and the quality of service provided is complicated in Ethiopia by two institutional features. First, the quantity of facilities, determined by the capital budget, is controlled by the Ministry of Planning and Economic Development, whereas the quality of services, determined by the recurrent budget, is controlled by the Ministry of Finance. The choice is liable to be more severely politicized than it would be if a single ministry were responsible for both types of expenditures. Second, most donors are precluded from funding recurrent expenditure and so, except through fungibility, increased donor funding is liable to shift the balance of expenditures toward facility provision rather than service quality. The tradeoff is intensified because capital expenditure not only has an opportunity cost in terms of contemporaneous recurrent expenditure but alters the subsequent composition of recurrent expenditure. Facilities have to be staffed, putting pressure on nonsalary recurrent expenditures.

The empirical analysis is based on a rural household survey conducted between 1994 and 1997 (see Dercon and Krishnan 1998 for details). Data are available from several rounds covering a panel of about 1,450 households and about 9,000 individuals. Detailed information on quality is available only for the first survey period (1994/95), except for a more limited number of villages (and therefore smaller sample), in which the health facilities were resurveyed just before the 1997 data collection round. We use mainly the data for the earlier period, but then use the smaller sample from 1997 to run fixed effects regressions, with varying quality, providing us with estimates for the quality effects, controlling for unobserved factors, such as fixed program placement effects.

The sampling frame was based on the major agro-ecological zones, focusing on the cereal-plough zones in northern, central, and southern Ethiopia; the enset complex; and the grain-hoe complex. Pastoralists and smaller zones were not included in this study. The sampled households cover 15 villages in an attempt to capture the different circumstances within different parts of each of the zones. The actual number of households chosen in each village reflects the population proportions. The relatively small number of villages was inspired by the practical constraints and costs of constructing high-quality longitudinal data and the desire to allow more detailed collection of community-level data. Attrition rates between 1994 and 1997 were about 5 percent. The sites chosen are very diverse in terms of wealth, agricultural resources, infrastructure, service provision, and so on. The resulting sample can be considered broadly representative of the population in these agro-ecological zones, covering more than 80 percent of the

7. Alderman and Lavy (1996) and Filmer, Hammer, and Pritchett (1997) discuss the problems with defining appropriate quality measures. Measures of infrastructure, drugs, and staff are commonly used. 
rural population, although care has to be taken in interpreting the results. The sample is more suited for understanding causal relations across different types of households and the evolution over time of indicators than the actual levels of, say, the regional distribution of disease or malnutrition.

The survey collected comprehensive data on health and a large number of individual, household, and community characteristics. The health data were selfreported and covered incidence and duration of illness, symptoms, and actions taken. The recall period was the preceding four weeks. On average about 10 percent of the population reported an illness episode and 52 percent sought treatment (table 1). ${ }^{8}$

Richer households are only slightly more likely to consult someone for treatment ( 50 percent for the richest quartile versus 44 percent for the poorest group). The poor rely disproportionately on pharmacies and the nearest clinics, whereas richer households rely on hospitals and more distant facilities. ${ }^{9}$

Hospitals, pharmacies, and clinics in Ethiopia can be owned by private agents, the government, or NGOs. In the survey, households were asked to specify whether the facility visited was a government facility, a private (and modern) or NGO facility, or a traditional site. In many areas private hospitals or clinics may be at a considerable distance, so there may be no effective choice as to whether public or private facilities are used. The state sector still strongly dominates health provision. About 75 percent of hospitals and 90 percent of health stations and centers belong to the government. More than 90 percent of pharmacies are private, however. In our sample the nearest health centers and clinics are almost always public. Hence the choice as to public or private facility is largely subsumed in the choice between pharmacies and other facilities.

Table 2 shows the distribution of visits to private and public facilities. ${ }^{10}$ More than 60 percent of the visits are to government facilities. ${ }^{11}$ The apparent lack of difference across consumption quartiles conceals the fact that for the poorest

8. As in other surveys, illness episodes are biased as a result of self-reporting. For example, there was very little difference between rich and poor households in the incidence of reported illness. Educated parents reported more illnesses of their children. The results appear consistent with evidence from the Welfare Monitoring Survey collected in $1995-96$ by the Central Statistical Authority. That survey is a nationally representative survey covering 7,000 rural and 4,000 urban households in 894 enumeration areas. It found that 19.4 percent of respondents in rural areas reported having been ill during the two months before the survey and that about 49 percent of them reported having sought treatment.

9. The Ministry of Health and many studies focusing on health facility usage consider visits to pharmacies not as visits to "modern facilities" but rather as forms of self-treatment, because in principle, diagnosis and treatment should be restricted to health clinics, facilities, or trained health workers. In the survey, households clearly did not make this distinction. In the econometric analysis, the implication of using a treatment definition including or excluding pharmacies is explored.

10. Data exclude traditional treatment. Private facilities include NGOs, which account for about 15 percent of visits to private facilities in our sample.

11. Data from the Welfare Monitoring System appear to suggest an even larger share of the private sector, with only 41.2 percent of those seeking treatment visiting a public facility in rural areas. 
Table 1. Venue of Treatment Sought When Ill, by Consumption Quartile (percent)

\begin{tabular}{lccccr}
\hline Item & Poorest & $\begin{array}{c}\text { Lower } \\
\text { middle }\end{array}$ & $\begin{array}{c}\text { Higher } \\
\text { middle }\end{array}$ & Richest & All \\
\hline No treatment & 54.6 & 52.0 & 51.7 & 49.8 & 52.0 \\
Nearest clinic & 21.6 & 18.9 & 20.4 & 19.7 & 20.1 \\
Nearest hospital & 4.7 & 8.6 & 6.5 & 9.5 & 7.4 \\
Hospital/clinic (not nearest) & 4.8 & 6.1 & 6.3 & 6.7 & 6.0 \\
Home of health worker & 5.0 & 4.1 & 5.0 & 6.4 & 5.1 \\
Pharmacy & 8.4 & 9.2 & 8.5 & 6.1 & 8.0 \\
Traditional healer & 1.0 & 1.2 & 1.7 & 1.9 & 1.4 \\
\hline
\end{tabular}

Source: Ethiopian Rural Household Survey, rounds 1-4.

group, pharmacies (the lowest tier of primary health care) are by far the most important source of private treatment, whereas for the richer groups, private health care includes a high proportion of visits by health workers at home or visits to private health clinics and centers.

\section{Estimation Results}

We use (reduced-form) demand relations for health care usage, distinguishing between distance to the facility, household and individual characteristics, and the quality of care, as in equation (6). People in different communities face differences in location and quality, even though the prices charged by clinics are uniform, some services, such as immunization, being free, and some having a low price (such as a 0.50 birr registration fee). Distances to health facilities are used to proxy the opportunity costs of getting to these services. Health stations or centers, the most important primary health care focal point in the health care system, are on average about $7 \mathrm{~km}$ from the villages; the nearest hospital is about $40 \mathrm{~km} \cdot{ }^{12}$

We include as explanatory variables a set of individual and household characteristics. Household income is proxied by household expenditure. We also control for the age and sex of the individual, as well as the age and sex of the household head and whether the mother completed primary school. Mean household expenditure in the sample is close to about $\$ 120$ per capita per year (63 birr per capita per month in 1994 prices). The education variable shows the extremely low levels of schooling in rural Ethiopia, with only 2 percent of mothers having completed primary schooling.

12. The mean distance to the nearest center-about 7 to $8 \mathrm{~km}$-is quite close to the average distances reported in the Welfare Monitoring System data in a nationally representative rural sample. The sample largely excludes pastoral and other lowland areas, which would have increased distance substantially. This mean distance is similar to the distance to public facilities in Kenya $(8 \mathrm{~km}$ in the data used in Mwabu, Ainsworth, and Nyamete 1993) and in Ghana (8.3 km in the data used by Lavy and Germain 1994). 
Table 2. Private and Public Facilities Visited for Treatment, by Consumption Quartile (percent)

\begin{tabular}{lccccc}
\hline Type of facility & Poorest & Lower middle & Higher middle & Richest & All \\
\hline Public & 62.7 & 63.2 & 57.2 & 63.7 & 61.8 \\
Private & 37.3 & 36.8 & 42.8 & 36.3 & 38.2 \\
\hline
\end{tabular}

Source: Ethiopian Rural Household Survey, rounds 1-4.

In addition to these standard explanatory variables, we introduce information related to the quality of health care provided in the health facilities available to the households in the sample. Measuring quality in health facilities is always difficult (Alderman and Lavy 1996, Filmer, Hammer, and Pritchett 1997, and Thomas, Lavy, and Strauss 1996). As in most other contributions to this literature, we focus on attributes that are necessary for the quality of care to be adequate rather than on quality differences above such a threshold. To provide adequate quality of service, a clinic requires functioning equipment, qualified staff, and a reliable supply of material inputs, such as dressings and drugs. We proxy each of these three attributes. The proxy for functioning equipment is whether the clinic has a functioning refrigerator with a back-up power supply. Two-thirds of public clinics had such a refrigerator. The proxy for the quality of staff is whether the clinic has a qualified nurse in regular attendance. In 1994 about two-thirds of the sample of government facilities had a nurse in regular attendance. The proxy for material inputs is whether the clinic reports receiving a regular supply of antibiotics. The current system for distributing drugs to primary facilities is indeed likely to produce large quality differences. Governmentand donor-financed drugs pass through distinct and uncoordinated systems, neither of which is responsive to needs. Primary (public) facilities do not purchase drugs from distribution systems, but rather receive such drugs as they are assigned. The lack of responsiveness of drug supply to need results in both persistent shortages and the persistent supply of drugs to locations where they are useless. Hence unsatisfactory quality is most likely the result of random failures in planned allocations (see Government of Ethiopia 1997). Only half the public clinics in the sample had a regular supply of antibiotics in $1994 .{ }^{13}$

There is wide variety in quality across facilities (table 3). Private health centers (including those run by NGOs) generally have better quality, but there are few of them, so that in many villages the nearest (and relevant) private facility is

13. Although the sample of health facilities is small, these measures are very close to the estimates from the 1995 survey by the sectoral investment office of the government of Ethiopia, which found that a quarter of public health stations and centers had no refrigerator and about half the public primary facilities lacked more than a quarter of essential drugs. 
Table 3. Frequency Distribution of Public and Private Facilities, by Level of Quality

(percent)

\begin{tabular}{lrrrrrrrr}
\hline & \multicolumn{2}{c}{1994} & & \multicolumn{4}{c}{ Panel 1994-97 } \\
\cline { 2 - 3 } \cline { 7 - 8 } Item & Public & Private & & Public 94 & Public 97 & Private 94 & Private 97 \\
\hline Equipment, inputs, and staff & 31 & 50 & & 0 & 21 & 50 & 50 \\
Equipment and inputs only & 0 & 0 & & 0 & 0 & 0 & 0 \\
Equipment and staff only & 5 & 0 & & 0 & 0 & 0 & 0 \\
Inputs and staff only & 16 & 0 & & 36 & 36 & 0 & 0 \\
Equipment only & 16 & 3 & & 21 & 29 & 0 & 0 \\
Inputs only & 12 & 0 & & 29 & 0 & 0 & 0 \\
Staff only & 11 & 0 & & 0 & 0 & 0 & 0 \\
None & 10 & 47 & & 14 & 14 & 50 & 50 \\
\hline
\end{tabular}

Note: Panel data for 1994-97 are based on four villages. In villages in which the only source of primary health care was a pharmacy (drug vendor), data refer to pharmacies. None of the pharmacies had a regular supply of antibiotics, a working refrigerator, or a regularly present, qualified staff (health worker, nurse, or doctor). Private facilities in the panel villages experienced no change in the quality indicators, so only one column is reported.

Source: 1994 and 1997 community-level surveys linked to the Ethiopian Rural Household survey.

a private drug vendor with very low quality. Only about a third of government facilities satisfy all the minimum quality criteria investigated.

Data on both facility characteristics and household characteristics were collected in 1994 from 15 villages. The reference period for facilities was for what was "typical" over the preceding 12 months. The households were surveyed three times during this reference period. The pooled dataset for these three rounds was then used in the regressions (allowing for the intertemporal dependence of errors using a random effects model). In 1997 both the facility and the household surveys were repeated in four villages. Because we have data on changes in quality for this subsample, we are able to test the robustness of the apparent effects of quality found in the cross-section analysis. In particular, by running fixed effects regressions, we can control for unobserved individual and community characteristics that may be correlated with health care quality (and other variables in the regression). If fixed program placement effects (such as the quality of health care being better in intrinsically wealthier areas populated with individuals with better health endowments) are present, the coefficients on quality variables in cross-section data are biased (see Rosenzweig and Wolpin 1986 for a classic discussion). Fixed effects regressions control for these fixed program placement effects, solving this problem. Because the coefficients are crucial for the analysis, the fact that we can do this is important, even though the subsample is relatively small. Although the potential for bias is well understood, such robustness tests are very rare because of lack of data. Note that neither the quality of private facilities nor the distance to health facilities changed in the subsample between 1994 and 1997 (no new building took place), so that the robustness of 
the results can be checked only with respect to the effect of the quality of public facilities.

Several different models are estimated to explain usage of modern health care services when one is ill. We use a set of individual and household characteristics, distance to and quality of the nearest private and public health facility, and a dummy, which is equal to one when the nearest public facility is a pharmacy. This control is introduced because we are interested in allocations in the health budget, which does not consider pharmacies as primary health care facilities, even though households appear to be using them as such. ${ }^{14}$ The first two models we estimate are simple probit models explaining usage among people who are ill, as well as the probit random effects model. The probit random effects model controls for constant individual-specific effects that are randomly distributed across the population, effectively allowing for serial dependence of errors across the same individuals in the panel.

We experimented by entering the three measures of quality in the usage regression both individually and as a composite. The composite is convenient because we can use it in later calculations of the cost of providing clinics of satisfactory quality relative to the benefits of increased usage. In building the composite we score the three attributes using the information in table 3 . The equal weighting is arbitrary. However, when each of the three components was entered separately, the results were not substantially affected. ${ }^{15}$

The empirical model used is a binary choice model focusing on whether treatment is sought or not. This choice needs justification. It is more usual to run a multinominal or nested multinominal logit model to explain the choices between different types of facilities (as in Gertler and van der Gaag 1990 or Lavy and Germain 1994), thereby revealing the substitution effects between different facilities. However, our focus is on how total usage of modern health care is affected. We seek to quantify the net effect of changes in the quality of and distance to the primary public facilities of health care on total usage (including clinics, pharmacies, and hospitals but excluding traditional healers). Thus substitutions between facilities are automatically netted out from our results. We discuss the implications of using a multinominal choice model.

The results of these two models, using the composite quality index, are quite similar (table 4). The strongest effects are as follows: Primary education of the main female adult increases health usage and so does higher real consumption per capita. Distance to a public facility reduces usage, but the effect of distance to a private facility is insignificant. The public facilities' quality index is signifi-

14. An alternative would have been to include only data on public and private health facilities that are not pharmacies, but this distinction was not made during data collection. Qualitatively, results on the key variables of interest are unchanged when excluding this dummy, although the fit is not as good.

15. Testing the joint restriction of equality of the coefficients on the three quality indicators for the public facilities revealed that equality could not be rejected at 1 percent. Individually, we typically found that the presence of a nurse in a public facility had no effect on usage, whereas inputs and equipment (drugs and refrigerators) had strong significant effects. 
TABle 4. Regression Results Explaining Health Care Usage, 1994-97 $($ dependent variable $=$ consulted modern facility when ill $)$

\begin{tabular}{|c|c|c|c|c|}
\hline \multirow[b]{2}{*}{ Item } & \multicolumn{2}{|c|}{$\begin{array}{c}\text { Model (1) } \\
\text { Probit (pooled cross-section) }\end{array}$} & \multicolumn{2}{|c|}{$\begin{array}{l}\text { Model (2) } \\
\text { Random effects probit model } \\
\text { (unbalanced panel 1994-97) }\end{array}$} \\
\hline & Coefficient & Probability $>|z|$ & Coefficient & Probability $>|z|$ \\
\hline Constant & -1.184 & 0.000 & -1.642 & 0.000 \\
\hline Age in months $/ 1,000$ & 0.546 & 0.263 & 0.763 & 0.096 \\
\hline Age squared/100,000 & -0.767 & 0.107 & -1.040 & 0.045 \\
\hline Sex & 0.063 & 0.364 & 0.108 & 0.158 \\
\hline Sex of head of household & 0.108 & 0.195 & 0.172 & 0.099 \\
\hline Age of head of household & -0.002 & 0.519 & -0.003 & 0.327 \\
\hline $\begin{array}{l}\text { Mother completed } \\
\text { primary school }\end{array}$ & 0.703 & 0.068 & 1.016 & 0.010 \\
\hline Household size & 0.012 & 0.506 & 0.016 & 0.193 \\
\hline $\begin{array}{l}\text { Log consumption } \\
\text { per capita (real) }\end{array}$ & 0.122 & 0.000 & 0.140 & 0.005 \\
\hline $\begin{array}{l}\text { Kilometers to nearest public } \\
\text { health care facility }\end{array}$ & -0.032 & 0.008 & -0.039 & 0.000 \\
\hline Quality index public & 0.383 & 0.069 & 0.539 & 0.000 \\
\hline $\begin{array}{l}\text { Kilometers to nearest private } \\
\text { health care facility }\end{array}$ & -0.001 & 0.944 & -0.001 & 0.822 \\
\hline Quality index private & 0.451 & 0.059 & 0.699 & 0.058 \\
\hline Dummy public pharmacy & 0.581 & 0.003 & 0.873 & 0.011 \\
\hline $\begin{array}{l}\text { Sample selection } \\
\text { Joint significance } \\
\text { Sample size }\end{array}$ & 78.73 & $2,317^{0.000}$ & $\begin{array}{l}81.06 \\
2,317 l\end{array}$ & $\begin{array}{r}0.000 \\
834 \text { groups) }\end{array}$ \\
\hline
\end{tabular}

Note: Errors corrected for cluster effects.

Source: Ethiopian Rural Household Survey, rounds 1-4.

cantly different from zero, while not significantly different from the private quality effects. We experimented with adding more variables into the equation, without changing the findings. For example, it may be argued that quality and facility presence are likely to interact in the demand for health care; that is, distance and poor quality may reinforce each other. However, multiplicative terms for private and public facilities were found to be jointly and separately insignificant when entered into the models. ${ }^{16}$

Marginal effects of the key variables for these models (as for several others) are reported in table 5 (evaluated at the mean). The first two rows give the marginal effects for the models reported in table 4. Broadly speaking, they are quite similar. For example, despite significant sample selection terms, the specification with and without sample selection has very similar marginal effects.

Using model (2) we find that having a mother who completed at least primary school increases health care usage about 35 percentage points. A 10 per-

16. For example, adding public and private quality times distance terms in model 2 gave $z$-values of 0.57 and -0.82 and $\chi^{2}(2)=1.43$ for their joint significance in the model (that is, no significant effects). 


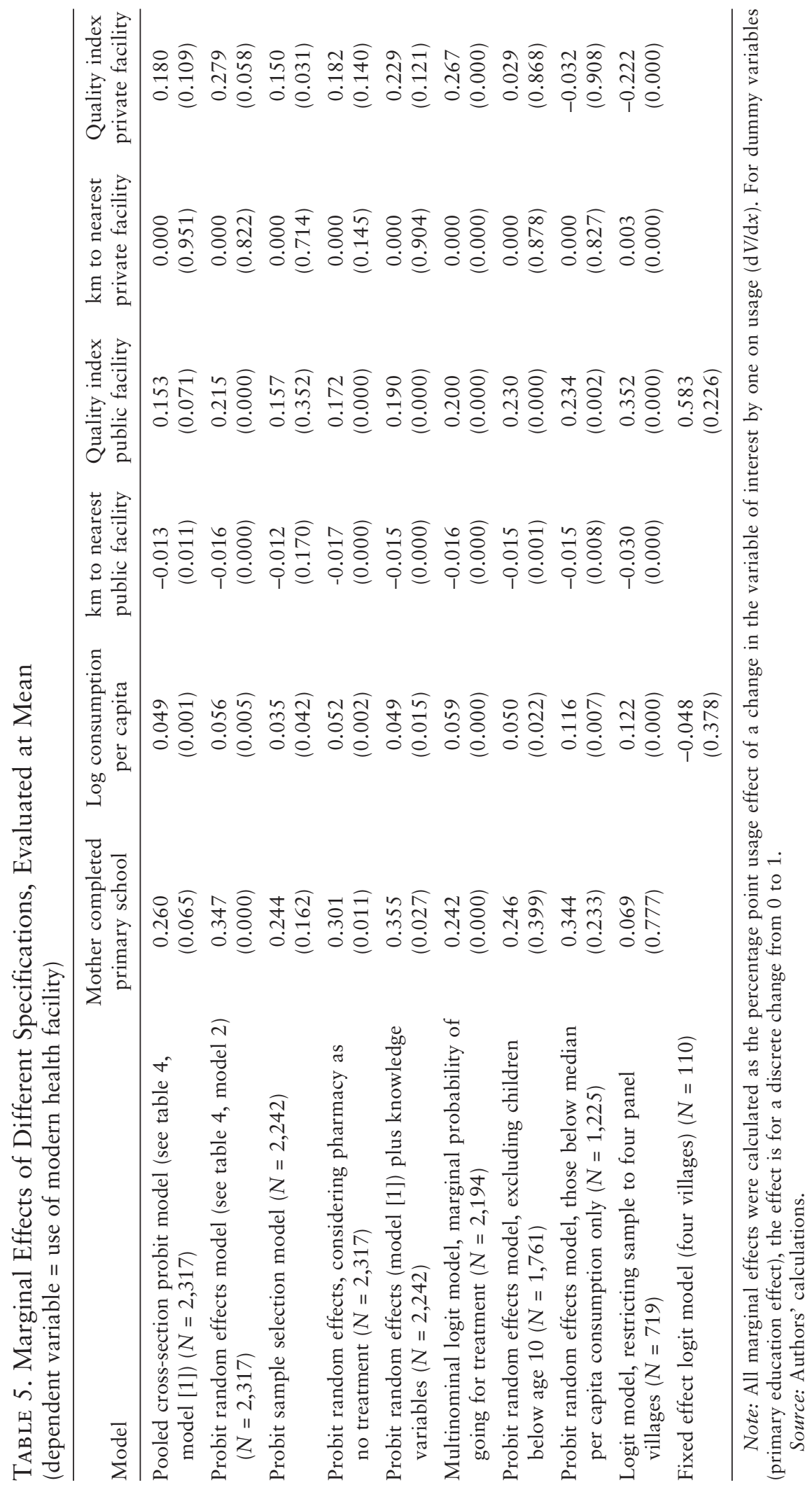


cent increase in consumption increases usage by almost 6 percentage points. A one- $\mathrm{km}$ closer public health facility increases use by 1.6 percentage points, whereas an increase in the quality of public facilities by a third (that is, one additional item in the index satisfied) increases usage about 5 percentage points. A similar effect applies to the quality of private facilities. The random effects formulation typically has somewhat higher estimates. However, in the rest of the article we are interested in the relative contribution of increasing usage by reducing the distance to or increasing the quality of health care facilities, and the relative marginal effects remain very similar across specifications.

The rest of table 5 looks into these marginal effects based on tests of the robustness of these results. The third row reports an attempt to control for possible self-selection problems associated with censoring the sample to those who are ill, by estimating a bivariate probit with sample selection with appropriate Heckman correction. We jointly estimate a selection equation and the usage equation, allowing for correlation in the errors and using this information in the usage equation as a control for selection (Greene 1993). The key issue is to find identifying instruments for the equation explaining self-reported illness. Although a reasonable expectation is that those households that are poorer and have less education would have a higher incidence of illness, data based on the selfreporting of illness do not typically find such a pattern. This is also the case here, suggesting that some of the problems related to self-reporting may have to do with information about illness, a fact that can be exploited to find appropriate instruments. In particular, we run a first-stage regression explaining illness using the same variables as in the usage regression plus variables describing health knowledge. In the survey the most important female household member (usually the spouse of the head or the head) was asked to identify the cause of diarrhea and malaria. The instruments used were variables based on whether these answers were correct or not, both directly entered into the regression and interacted with consumption and education variables. Knowledge as an identifying instrument may not be fully convincing, but even so, the robustness of the findings is striking. ${ }^{17}$

Row 4 displays the results when visits to pharmacies are not treated as modern health care visits; row 5 considers a specification including health knowledge variables (as in the selection equation in row 3). Both models give very similar marginal effects as before. ${ }^{18}$ A multinominal specification (using a multinominal

17. As always in selection models, it could be argued that illness knowledge will also contribute to whether an ill person seeks treatment, making the usage model misspecified (if left out) or the selection equation identified only by distributional characteristics (if included in the usage equation). This problem cannot be solved. Furthermore, knowledge may be a function of past usage. If it is, this variable measures past usage. The high significance is therefore not surprising, and the variable is not very convincing as an identifying instrument.

18. The specification displayed in row 5 suggests that controlling for wealth, education, and facility characteristics, the return to health knowledge is high: Knowing the cause of diarrhea increases modern health usage 5 percent, while knowing the cause of malaria increases modern health usage 4 percent. 
logit with choices of no treatment, treatment in private facilities, and treatment at public facilities) did not give different results. Restricting the sample to adults and investigating whether the poor behave differently also revealed little difference, especially in the variables related to public health facilities.

The last two rows warrant more discussion. A major potential shortcoming of this analysis is that quality and distance effects are measured without taking account of the fact that facilities may not have been randomly placed. In particular, planners may have located them according to characteristics unobserved by the researcher that are correlated with the determinants of health and health usage, biasing estimates on the variables of interest. To the extent that these unobserved characteristics are fixed, fixed effects models can deal with this problem. We used a fixed effects logit model on the four villages for which we have information. For comparison, we first gave the logit for this restricted dataset. The sample is very small to obtain good point estimates of the various marginal effects. In general, the logit model gives larger marginal effects on quality and distance of public facilities, although in relative terms the effects are still very similar. The fixed effects regression can give some indication of the bias involved as a result of program placement (or indeed any other missing fixed characteristic). The sample becomes restricted to people who were ill in at least 2 of the 4 periods and who experienced a change in health usage in this period. Only 110 observations satisfy these conditions, and only household size, consumption, and quality of public health facilities appear to change in this period. Quality changed in only 2 of the 4 villages, so this is indeed a small sample to pick up any effects.

In view of this, the results are quite interesting. We find a positive (albeit not quite significant) correlation between quality and usage. The effect was larger than the effect in the simple logit on the four villages (and outside the implied 95 percent confidence interval by this model). This suggests that the quality effect is underestimated due to placement effects; that is, an unobserved effect that contributes positively to usage is negatively correlated with the quality indicator. For example, if the unobserved effects are linked to wealth, then the supply rule of facility quality may have favored poorer areas. Because we do not observe new facility building (and therefore change in distance) in the sample, we cannot investigate further the placement effects related to distance. Even so, the results of the fixed effects model suggest that we may well be underestimating the contribution of quality to health usage, biasing the results in favor of allocating public expenditure toward reducing distance rather than increasing quality.

Thus both the distance and the quality aspects of the shadow price of usage have significant effects on demand. It is possible to compare these effects more directly. Restricting the discussion to the point estimates using the full sample, the marginal effect of increasing the index of quality from zero to one is $15-21$ percent. A reduction in distance by one $\mathrm{km}$ increases usage by 1.2-1.7 percent. Obviously, these are only point estimates-for example, taking the marginal effects using the random effects model suggests a 95 percent confidence interval of about 12-31 percent for quality increases from zero to one, and a $0.8-2.3$ 
percent increase of usage by reducing distance to public facilities by one km. ${ }^{19}$ Another way of looking at the results is to consider the impact on usage of bringing all clinics up to the quality standard of "fully satisfactory." 20 The effect on usage would be considerable, with demand increasing 9.3 percentage points (using model [2]). The same effect on demand could be achieved by reducing the mean distance to clinics $5.9 \mathrm{~km} .{ }^{21}$ In the next section we compare the costs of increasing usage by improving quality and by reducing distance.

\section{Budgetary Costs and the Density-Quality Choice}

The decision to build more facilities or improve the quality of existing facilities has been decentralized to local government in Ethiopia. Currently, about 43 percent of the health budget is being devoted to building more facilities, so this is probably the single most important choice in health care budgeting. ${ }^{22}$ We now show how the results on usage can be combined with local information to yield a workable decision rule at the local level and show that it is likely to change budget decisions substantially.

Recall from condition (17) that one condition for an allocation to be optimal is that the marginal dollar spent on improving quality must have a smaller impact on usage than the marginal dollar spent on increasing the number of facilities. We consider these two marginal effects in turn.

The marginal effect of expenditure on quality improvement can be decomposed into two terms:

$$
\frac{d V}{d E_{q}}=\frac{d Q}{d E_{q}} \cdot \frac{d V}{d Q}
$$

where $E_{q}$ is public expenditure on quality of provision.

In the previous section we measured $Q$ on the six-point scale shown in table 3 and estimated the second term on the right-hand side, $\mathrm{d} V / \mathrm{d} Q$. Using informa-

19. It is possible to compare these results with Ghana. Lavy and Germain (1994) show that the net increase in use of (public and private) health facilities from bringing drugs, infrastructure, and service to "optimal" levels in public facilities was equal to 3 percentage points. Because quality appears to be substantially lower in the Ethiopian public health service, the effects appear comparable. Similarly, the effect of halving the distance to the nearest public health facility increased the usage of health facilities by 5 percentage points at the mean. In Ethiopia the effect of halving distance would be equivalent to about 4.1 percentage point.

20. We also looked at the effects for different quality items by introducing them in the regressions rather than the composite index. We found that the move to full drug availability would increase usage 3.6 percent and installing and repairing refrigerators in all public facilities would increase usage about 6.6 percent.

21. Other regressions give very similar relative effects. Using the extreme point estimates of marginal effects implied by table 5 for the full sample, we found that increasing demand by bringing all public facilities up to full basic quality could also be obtained by reducing distance $3.8-7.7 \mathrm{~km}$. The values implied by the confidence interval would suggest $2.2-16.9 \mathrm{~km}$. These values can be used to investigate the robustness of the results in the next section.

22. Figures are for 1997-99, before actual capital expenditures (World Bank 2000). 
tion at the regional level, it will usually be straightforward for a budget agency to estimate the first term, the cost of achieving a marginal quality improvement in the health facilities in a locality. Here we illustrate using a crude nationallevel approximation. We stress that our purpose is primarily illustrative: information at the level where such decisions are routinely made will always be superior to these national-level data.

Nationally, health costs are not available at the level of disaggregation used in table 3, forcing us to rely on inferences from the total cost of clinics. Even at this level of aggregation the data are problematic because not all components of expenditure are channelled through the budget. The total cost of providing the current level of primary health care quality in the public sector is the total recurrent expenditure on primary health care plus off-budget recurrent expenditure on drugs less revenue from user charges, which is largely in the form of charges for drugs. Recurrent expenditure on primary health care (that is, for health centers and clinics plus some allocation for health programs and management) in the 1994/95 budget was 138 million birr (World Bank 1995). However, in 1994 most of Ethiopia's drug supply was provided off-budget by donors. Although (remarkably) there is insufficient financial information to provide an accurate costing of this provision, we estimate that the cost of drugs net of recovered costs is approximately equal to the value of gross expenditure on primary care by the government. Hence we estimate the total gross cost of primary care at about 276 million birr (see Government of Ethiopia 1997). ${ }^{23}$ This expenditure, distributed over the 2,010 primary health stations, purchases the current frequency distribution of quality of primary health care (so that the unit cost of a facility is 137,300 birr).

Using the six-point quality scale of table 3 , which ranges from 0 to 1 , the population-weighted mean level of quality is 0.60 . For purposes of illustration we assume that the cost of health care quality is linear in this index. Thus raising average quality from 0.6 to 0.7 would require an increase in the gross cost of primary care of one-sixth, or 46 million birr. From the coefficient on quality in the random effects usage regression (model [2]), this increase in quality would raise usage by 2.6 percent. ${ }^{24}$ Analogously, an increase in expenditure on quality improvement of 10 million birr per year would increase usage about 0.6 percent.

23. The data indicate that this is likely to be an overestimate. One report estimates the total value of drugs supplied in Ethiopia at about 360 million birr (Mengesha 1996). Using the right-hand-side data we find per capita expenditure on drugs of about 8 birr a year, equivalent to about 400 million birr a year-somewhat higher than Mengesha's estimate. Very few people are exempt from charges for drugs and treatment in rural Ethiopia. Data from the right-hand side indicate exemption rates at health stations and centers of less than 10 percent. Unpublished data from the sectoral investment office at the Ministry of Health suggest somewhat higher exemptions rates, but even those data show that just 1227 percent of patients were exempt. At the current level of quality at health facilities, households are often dependent on private pharmacies for drugs. Taken together, this would support the view that offbudget financing of drugs is lower in net terms than the estimate used in the evaluation-that is, we overestimate the cost of quality.

24. Later we discuss the sensitivity of the results to using different estimates. 
Making such a calculation at the national level is difficult; in any particular local situation it will be much easier. There will be a limited number of clinics, most of which will be of satisfactory quality, and a few (typically about a third) will have identifiable deficiencies, such as lack of trained staff or deficient equipment, for which the cost of rectification can reasonably be estimated. Hence the cost of quality improvement is not an intrinsically difficult number to estimate; it is simply problematic to arrive at a national average cost from national data.

We next consider the effect of an increase of 10,000 birr in expenditure on the provision of facilities. The marginal effectiveness of such expenditure can be decomposed into three terms:

$$
\frac{d V}{d E_{f}}=\frac{d N}{d E_{f}} \cdot \frac{d D}{d N} \cdot \frac{d V}{d D}
$$

where $E_{f}$ is public expenditure on facility provision and $N$ the number of facilities.

The first of the three terms in equation (19), the cost of an additional health unit, consists of the annual cost of running the unit and the amortized cost of its construction. We have already calculated the cost of running a unit at 137,300 birr. The amortized cost of construction can be inferred from government estimates of the construction cost of a primary health care complex (a set of five rural health stations or clinics, managed by a health center, usually located in an urban center). The unit cost of building such a complex, as budgeted in the government's health plan, is 1.5 million birr, or 300,000 birr per health station (Ministry of Health 1995). We convert this into an annualized cost assuming a discount rate of 10 percent, yielding an annual cost of 30,000 birr. ${ }^{25}$ Hence the approximate total annual unit cost of an additional primary health facility is 167,300 birr.

We now turn to the second term, the relation between the number of facilities and the mean distance to a facility. In any particular local situation this is a simple matter. Given the location of existing facilities and the distribution of the population, there will be some site for a proposed facility that will maximize the reduction in the distance of potential users. The reduction in distance achieved by the proposed location is then a straightforward calculation. To illustrate using national data requires some simplifying approximations.

Suppose that the allocation decision in question is to build several new facilities to provide coverage to a district that has previously not been served and over which the population is evenly distributed. The decision problem is to determine the appropriate number of facilities, $N$. The district covers an area of $C$ square $\mathrm{km}$. Each facility will serve a catchment area $C_{f}$, and between them the facilities will serve the entire area, so that

25. The Ministry of Economic Development and Planning estimates the cost of building five health stations and a health center at almost 3.4 million birr. It uses much lower depreciation rates for buildings, so that the annualized cost is about 45,000 birr per health station. Building health stations without a supporting health center would be cheaper, at an annualized cost of about 20,000 birr. 


$$
N C_{f}=C .
$$

Because the total area to be served is given, any change in the number of facilities must have an offsetting proportionate change in the catchment area:

$$
d \ln N+d \ln C_{f}=0 .
$$

We approximate $C_{f}$ by the circular area $\pi r^{2}$, where $r$ is the radius of the catchment area. In this case the mean distance of users to the facility, $D$, is determined as $2 r / 3$. The term $\mathrm{d} D / \mathrm{d} N$ is more conveniently analyzed as an elasticity, $\mathrm{d} \ln D /$ $\mathrm{d} \ln N$. This can be decomposed into two simple terms:

$$
\frac{d \ln D}{d \ln N}=\frac{d \ln C_{f}}{d \ln N} \frac{d \ln D}{d \ln C_{f}}=\frac{d \ln \pi r^{2}}{d \ln N} \frac{d \ln (2 r / 3)}{d \ln \pi r^{2}}
$$

From equation (21), the first term on the right-hand side of equation (22) is minus unity, and the second term is 0.5 . Hence a 1 percent increase in the number of facilities reduces the mean distance to a facility by 0.5 percent. ${ }^{26}$

The third term in equation (19) was estimated in the usage regression. According to the random effects probit, a reduction in the mean distance to a facility of 0.1 $\mathrm{km}$ increases usage by 0.12 percent. Given the current mean distance to a facility, this is a reduction of about 1.7 percent. Such a reduction in the mean distance would require an increase in the density of facilities of 3.5 percent (that is, $1.017^{2}-1$ ).

The cost of a 3.5 percent increase in the number of facilities is 12 million birr a year. Hence an increase in expenditure on the provision of facilities of 10 million birr would increase usage about 0.1 percent.

Bringing the analysis together, an increase in expenditure of 10 million birr would raise usage about 0.6 percent if spent on quality improvement but only about 0.1 percent if spent on more facilities. Thus given the current allocation of the budget, quality improvement appears to be more effective in increasing usage than building additional facilities. ${ }^{27}$ Yet we know from equation (17) that

26. To see this more intuitively, imagine the proposed facilities arranged on a grid pattern. To halve the average distance to a clinic, it is necessary to reduce the scale of the existing grid by half. This implies reducing the catchment area of each facility by a factor of four. Hence a halving of distance requires a quadrupling of the number of facilities. A similar result holds for the hexagonal catchment areas, which Losch (1954) shows to be optimal. Were the population and clinics strung out along a single line of road like beads on a string, the mean distance could be halved simply by doubling the number of clinics. However, about half of the rural population is living in villages that are not even connected by all-weather roads.

27. The point that spending on quality appears more effective than spending on reducing distance remains valid if any of the alternative estimates discussed in section III is used. For example, using any combination of the other point estimates for the marginal effects, the impact from spending on quality is always at least twice as large as the impact from distance reduction. The 95 percent intervals of the point estimates of the models used do not change the conclusion, although the difference becomes smaller. For example, the intervals of the marginal effects based on the random effects model (model [2]) suggest that even the lowest marginal effect from quality and the highest marginal impact from density would imply that increasing usage by increasing density is still 50 percent more expensive than increasing usage by improving quality. 
this cannot be optimal. Because improving health outcomes rather than usage is the policy objective, once expenditure is efficiently allocated a marginal increase in spending on quality improvement will increase usage by less than if the money were spent on more facilities. Hence nationally the current budget allocation appears to be too heavily skewed toward provision of facilities.

We have stressed that the national level data are primarily illustrative. The conclusion that the budget is currently misallocated indeed rests on heroic assumptions. Nevertheless, the analysis suggests that sizable gains might be achieved in the efficiency of health expenditure if local budget decisions applied the decision rule set out herein. The results suggest the limits of increasing health care usage through changes in the health budget. Both expenditure reallocation and expenditure increases appear to have relatively modest effects on usage. Maternal education and household income both affect usage quite substantially. Hence education and rural development policies may be even more important for health usage objectives than health care policy itself.

\section{Conclusion}

This article provides a decision rule for choosing between the quantity and the quality of health care provision that could be applied at the local level. Using national data, we show that current priorities are unlikely to be cost-effective. Based on analysis of a large-sample rural household survey, we find that household usage of health facilities is sensitive to the quality of health care as well as to the distance to the nearest public facility. Given the current budget allocation, it appears to be considerably less costly to increase usage by improving quality than by bringing facilities closer to people. Health outcomes rather than usage are the ultimate concern of policy, and quality improvement directly improves both health outcomes and usage. In an efficient budget allocation, expenditure on building facilities would be reduced to the point at which its effect on usage was greater than that of expenditure on quality improvement.

\section{REFERENCES}

Akin, John S., C. Griffin, D. Guilkey, and B. Popkin. 1986. “The Demand for Primary Health Care Services in Bicol Region of the Philippines." Economic Development and Cultural Change 34(4):755-82.

Akin, John S., D. Guilkey, and H. Denton. 1995. "Quality of Services and Demand for Health Care in Nigeria: A Multinominal Probit Estimation.” Social Sciences and Medicine 40(11):1527-37.

Alderman, Harold, and V. Lavy. 1996. "Household Responses to Public Health Services: Cost and Quality Tradeoffs." World Bank Research Observer 11(1):3-21.

Appleton, Simon. 1998. "The Impact of Public Services on Health Care and Illness: A Treatment Effects Model with Sample Selectivity." Journal of African Economies 7(1):1-33. 
Behrman, Jere R., and A. Deolalikar. 1990. "Health and Nutrition." In H. Chenery and T. N. Srinivasan, Handbook of Development Economics. Vol. 1. Amsterdam: North Holland.

Central Statistical Authority. 1999. WMS 3-98: Report. Addis Ababa.

Dercon, Stefan. 2000. "Poverty and Deprivation in Ethiopia." Background paper for Poverty Assessment of Ethiopia. World Bank, Africa Region, Washington, D.C.

Dercon, Stefan, and P. Krishnan. 1998. "Changes in Poverty in Rural Ethiopia 198995." CSAE (Centre for the Study of African Economies) Working Paper wps 98/7. Oxford University, CSAE.

- 2000. "In Sickness and in Health: Risk Sharing within Households." Journal of Political Economy 103(4):688-727.

Dor, Avi, and J. Van der Gaag. 1988. "The Demand for Medical Care in Developing Countries: Quantity Rationing in Rural Côte d'Ivoire." LSMs Working Paper 35. World Bank, Development Research Group, Washington, D.C.

Filmer, Deon, J. Hammer, and L. Pritchett. 1997. "Health Policy in Poor Countries: Weak Links in the Chain." Policy Research Working Paper 1874. World Bank, Development Research Group, Poverty and Human Resources, Washington, D.C.

Gertler Paul, and J. Van der Gaag. 1990. The Willingness to Pay for Medical Care: Evidence from Two Developing Countries. Baltimore: Johns Hopkins University Press for the World Bank.

Government of Ethiopia. 1997. Ethiopia Social Sector Review: Public Expenditure Review II. Addis Ababa: Ministry of Finance.

Greene, W. H. 1993. Econometric Analysis, 2nd ed. New York: Macmillan.

Hotchkiss, D. 1993. "The Role of Quality in the Demand for Health Care in Cebu, Philippines." University of North Carolina, Department of Economics, Chapel Hill, N.C.

Lavy, Victor, and J.-M.Germain. 1994. "Quality and Cost in Health Care Choice in Developing Countries.” LSMS Working Paper 105. World Bank, Development Research Group, Washington, D.C.

Lavy, Victor, J. Strauss, D. Thomas, and P. De Vreyer. 1996. "Quality of Health Care, Survival, and Health Outcomes in Ghana." Journal of Health Economics 15(3):333-57.

Litvack, Jennie I., and C. Bodart. 1993. "User Fees and Improved Quality of Health Care Equals Improved Access: Results of a Field Experiment in Cameroon.” Social Science and Medicine 37(3):369-83.

Losch, August. 1954. The Economics of Location. New Haven, Conn.: Yale University Press.

Mengesha, Yishak. 1996. "Issues and Problems in the Production, Import, and Distribution of Pharmaceutical Products in Ethiopia." Background Paper for the Social Sector Review PER II. Ministry of Finance, Addis Ababa.

Ministry of Health, Ethiopia. 1995. "Health Sector Development Programme: A 20-Year Long-Term Plan Framework.” Planning and Programming Department, Addis Ababa.

—. 1999. "Health and Health-Related Indicators 1991 E.C." Planning and Programming Department, Addis Ababa.

Mwabu, Germano, M. Ainsworth, and A. Nyamete. 1993. "Quality of Medical Care and Choice of Medical Treatment in Kenya: An Empirical Analysis." Journal of Human Resources 28(4):838-62. 
Rosenzweig, Mark R., and K. Wolpin. 1986. "Evaluating the Effects of Optimally Distributed Public Programs: Child Health and Family Planning Interventions." American Economic Review 76(3):470-82.

Strauss, John, and D. Thomas. 1995. "Modelling Human Resources." In J. Behrman and T. N. Srinivasan, eds., Handbook of Development Economics. Vol. 3A. New York: Elsevier.

Thomas, Duncan, V. Lavy, and J. Strauss. 1996. "Public Policy and Anthropometric Outcomes in the Côte d'Ivoire." Journal of Public Economics 61(2):155-92.

World Bank. 1995. Ethiopia Public Expenditure Review: Issues in Public Expenditure. Vol. I. World Bank, Africa Region, Washington, D.C.

. 1996. African Development Indicators. World Bank, Africa Region, Washington, D.C.

2000. Ethiopia Public Expenditure Review, Vols. I and II. World Bank, Africa Region, Washington, D.C.

wHо (World Health Organization). 2000. World Health Report. Geneva. 